\title{
COMPETITIVENESS OF SATV IS MEASURED BY CERTAIN FACTORS IN THE BANGLADESHI TV INDUSTRY
}

\author{
Talukder, M.N.H \\ SA Channel Pvt Ltd, Bangladesh
}

\begin{abstract}
Branding is the only element in marketing and advertising area through which any organization can differentiate themselves from others and strategize their initiatives accordingly. SA Channel Pvt Ltd is the first ever high definition (HD) executed channel among all the infotainment television industry who has already created some differentiation in making drama, news, films, talk shows \& experimental productions etc and the result was quite obvious in the national viewership report in recent times. In spite of having a huge parallel competition in the industry, it has been proving its differentiation in televising better quality programs chasing up with some giant ones since from the inception of its glorious journey. In my whole paper I will utilize the quantitative research approach and in order to get the at most unbiased findings where at least 10 giant competitors will be invited in an open interviewing session who will be allowed to give their opinion individually to find out the efficiency of strategizing individual brands along with some in depth comparative and competitive analysis of our television industry in recent time through investigating it's various related dependable factors that are connected with the executing or implementing tools of building brand image gain the competitive and first mover advantage in media industry.
\end{abstract}

Keywords: Branding, SA Channel Pvt Ltd, High Definition (HD), Infotainment television industry, Differentiation, viewership, competition, unbiased, first mover advantage.

\section{INTRODUCTION}

SA Channel Pvt Ltd (Sister Concern SA group) started its journey in the broadcasting media industry on $19^{\text {th }}$ of January, 2013 following a particular mission and vision toward the goal of televising and creating a differentiation in the market compared to competitor's initiatives with high definition (HD) screen and highly equipped technologies and expert manpower in all the departments.

Strategizing brands carry some direct and indirect meanings and different approach of market positioning. The competitive stands of SA Channel Pvt Ltd will be clarified through analyzing their different ways of strategizing and brand positioning in order to hold a better position according to the survival point of view competing with the other

Corresponding author email: thensuovi@gmail.com players in the same industry.

The whole research will be diagnosed through sitting the face to face interview session with the prominent personalities who are acting as competitors in the infotainment industry of Bangladesh. In the open session they were asked some questions regarding their individual implemented and executed strategy in order to gain the competitive and first mover advantage through establishing their brand identity among all the competitors with parallel market operation. In the session they rated their competitors through their own point of view.

Couple of factors was being focused in interviewing session. Some questions required and demanded some descriptive answers and were emphasized to justify their self defensive points considering their competitor's strategy with executions and implementation. All these efforts were given to find out the total pathway of strategizing brands for competitive stands of SA Channel Pvt Ltd. 


\section{CONCEPTUAL FRAMEWORK (QUANTITATIVE)}

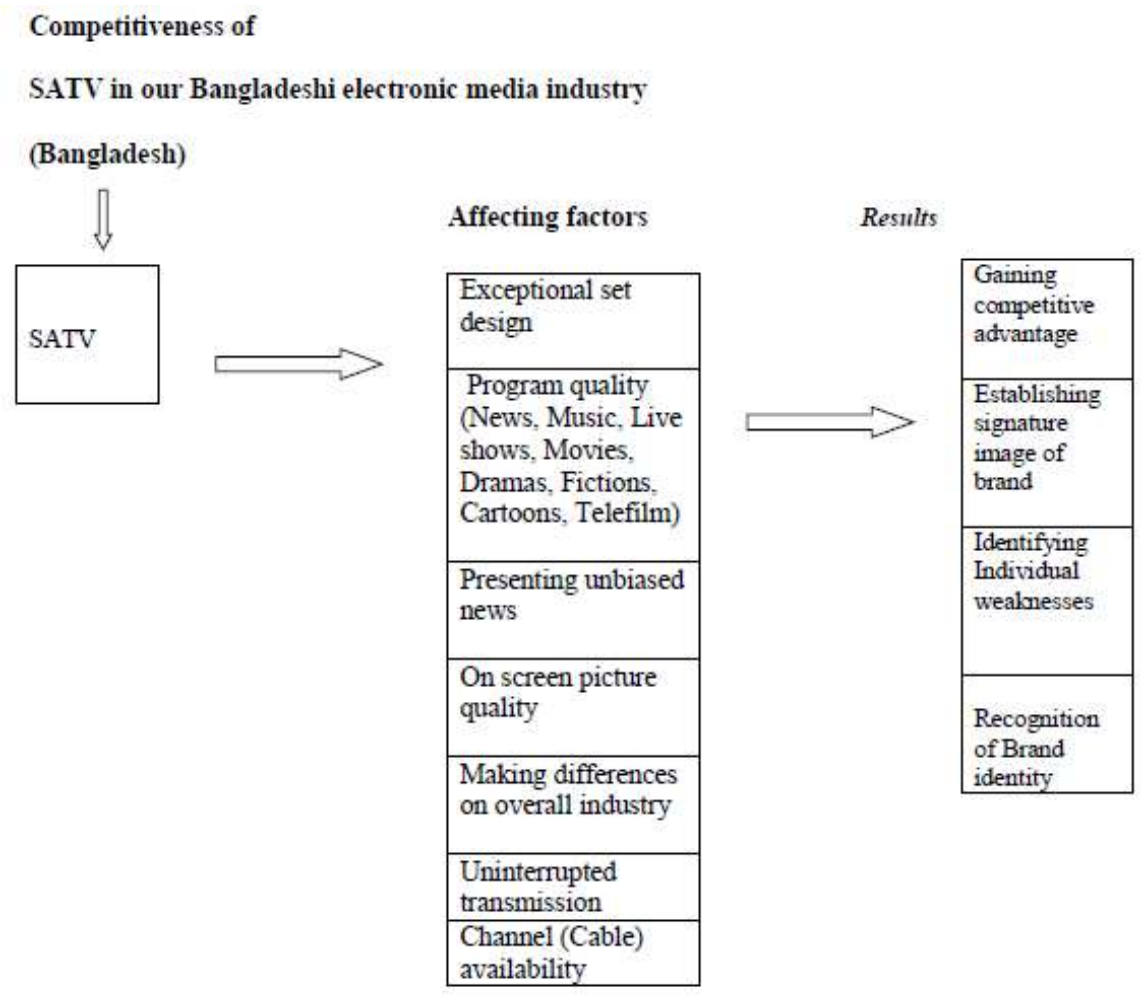

\section{RESEARCH PROBLEM}

How the electronic media industry of Bangladesh is strategizing and surviving to gain the competitive and first mover advantage over each other?

\section{RESEARCH OBJECTIVE}

The government is allowing too many competitors to play in this industry since the market size is unchanged and this is creating problem in terms of survival point of view. This research is going to be analyzed to give the comparative explanation to demonstrate that how our electronic infotainment industry is strategizing them to survive in the market individually in order to figure out the strategizing brands of SATV for its competitive stand and how they are currently implementing these strategies accordingly.

\section{RESEARCH BACKGROUND}

The ministry gave its approval a few days ago for issuing licenses to those who it deemed qualified. The Awami League-led alliance government gave approval to 13 new television channels, 14 FM radios and around 60 Community Radios just before stepping down from office. Following the final approval, the information ministry gave its permission to issue licenses to credible and qualified applicants.

The Awami League government of Bangladesh had previously approved $18 \mathrm{TV}$ channels. Of those, on October 20, the government approved Channel Bayanno and on November 6, Bangla TV. Jamuna TV got its licence back on Jul 29 this year. In October 2009, the government gave the permission to Ekattor TV, Mohona Television, Channel 9, Somoy TV, GTV, Independent Television, Maasranga Television, ATN News, My TV and Bijoy TV while Channel 24, SA TV, Asian TV, Dipto Bangla Television and Gan Bangla were awarded licences in 2010.

http://www.dhakatribune.com/bangladesh/2013/nov/2 7/13-tv-14-fm-radio-stations-get-licence 


\section{INTERVIEWING SESSION}

The brief interviewing session are chronologically described as follows in alphabetical order. The following data were gathered through talking face to face with 100 different samples including filling out a questionnaire from 12 different television channels:

\section{Asian TV}

In order to grab viewer's attention SATV is trying to produce colorful drama on the basis of Indian mega serial pattern and they have already created that milestone.

They are televising live musical programs 365 days throughout the year and have their individual FM station that are boosting up and adding their initiatives to achieve competitive and first mover advantage.

They discovered the threatening part of the channel is lack of technical support service and unorganized operational activities

They rated SATV in a better position in the electronic industry in studio set up and external outlook with differentiated set design.

\section{ATN Bangla}

ATN Bangla is strategized to devote itself serving mid level and root level viewers and it co-ordinate the marketing activities and synchronizes their program segments accordingly. On the basis of its target audience and channel positioning he considers ATN a successful channel where no other channels are considered to be their competitor who has strategized their products, promotions \& brand in a parallel way especially in the segment of films and serial drama.

They also mentioned that the dominance of Indian channels and copying its pattern in all of our national programs are becoming a threatening element in our electronic media industry.

They appreciated SATV's better screen quality than any other channel. They also rated it in higher position in the arena of overall program presentation which is quite more impressive and eye catching to watch.

\section{Baishakhi TV}

Though Baishakhi TV doesn't have any particular brand identity for any segment of program, once it had an image of executing some big events with arranging mega entertaining live shows with Indian superstar Shahrukh Khan, Salman Khan, Akshay Kumar during 2010 and 2011 through the interference and support of its mother company Destiny Group but after that it has been suffering from the problem of not utilizing the financial back of it since the managing director of destiny group is kept in prison for political reason and only for that reason they couldn't take further initiatives for reinvestment of any prospective programs that is causing them to hunt first for getting sponsorship of any program before implementing and executing.

They acknowledged SATV's financial strength of reinvesting any programs because SATV first approves the program budget themselves and starts producing it even before hunting the sponsorship from market without taking into consideration the profit and loss matters. They appreciated SATV's status technological advancement especially for execution of HD technology. They praised SATV's entrepreneurship of arranging big budgeted events like Bangladeshi Idol with bigger and more beautiful set.

\section{Bangla Vision}

Bangla Vision is the $2^{\text {nd }}$ satellite channel in Bangladesh after national television who televises Azan everyday 5 times for awaking the devout Muslim community to say their prayers at mosque and they manage that time cutting it from their usual TVC time that built a different identity and deserves appreciation.

On the other hand they have captured the whole market in televising dramas throughout the year and placed almost an unbeatable and unparallel position in the electronic media industry. They showed his deep concern for facing pressure of the too many competitor as too many channels in recent time have got their entry pass in the electronic industry though the financial market size remains same.

They rated SATV as technologically advanced channel specially for executing the HD technology for ensuring its better screen quality 


\section{Channel I}

Channel I became pioneer and got the first mover advantage in the in the genre of talk and agricultural, environmental and ethnic documentary program. In the category of model and kids musical talent hunt reality show it has the immense reputation like. The team introduced very first in Bangladesh different types of analyzing news segment and documentary based Islamic travel program.

They showed his disappointment and rated 'very weak' in the side of drama. To him it's very lower in quality compared to other channels. The management is taking it into consideration for its improvement.

They considered SATV better compared to them in the category of dance related programs, Islamic programs. They considered SATV as one of the leading channel in the area of screen quality which is genuine HD.

\section{Channel 9}

Channel 9 considers GTV as one of their competitors as both of their product segmentation is same that is sports specially cricket. Since GTV got their right from Bangladesh cricket board (BCB) in June, 2014 to televise cricket for 5 years, Channel 9 couldn't properly capture their market through cricket which was dominantly under control of them before that. Currently they are strategizing to get hold of sports right in other segment of cricket like Bangladesh Premier League.

They considered SATV in a better position in the area of HD screen quality including its high quality of drama and appreciated SATV's initiatives to televise the world famous talent hunt reality show 'Bangladeshi Idol'.

\section{ETV}

ETV holds a better position especially in the area of talk shows and news.

They added that ETV faced some transmission problems in some areas due to some unavoidable internal problems. When they were asked some personal questions about their present they mentioned that although they are committed to deliver accurate news to the common people, only because of the present political unrest conditions they are gradually losing that right and becoming unable to present unbiased news.

They congratulated SATV's entrepreneurship initiative for organizing a world class big reality talent musical reality hunt show 'Bangladeshi Idol' ever first in Bangladesh on its screen.

\section{GTV}

GTV doesn't consider anyone to be their competitor as their strategic product segmentation track is based on sports emphasizing sports especially cricket besides other entertaining programs and consequently its target viewers are far more different and unique than others creating a massive impact on viewer's choice and gaining first mover competitive advantage. To them GTV don't have any special problems that could be noted ahead except not getting proper sponsorship at the right time on the basis the level of their segmented expectation that are predicted from a certain level of sources.

They considered SATV a better position in the area of bigger space management for designing a better set. They appreciated its news team co-ordination and congratulated the program team for producing special programs of different celebrating events like Valentine's Day, yearend concert, and birth and death anniversary of our national personalities etc.

\section{Massranga TV}

Massranga TV have targeted their viewers group from middle class to upper-upper class and it has positioned and adjusted their channel and product positioning accordingly with strict supervision and maintenance and that is why it gets extra favor in getting sponsor from outside financer.

They also explored that it has some extra advantage from the reputation of their mother company 'Square Group' as people have a good faith on it and its products which led toward gaining a positive attention of the viewers and it became interrelated in building their signature image.

They appreciated SATV's HD screen quality along with its non compromising financial initial initiatives from own fund with every program before running 
into the market with a view to ensuring quality productions.

\section{NTV}

NTV doesn't consider anyone to be their competitor. They are still on their way to improve the quality of the program and make the some differences in Bangladeshi electronic industry so that no one could come forward to beat them and take parallel initiatives and strategy to gain the first mover attempt. They considered NTV as a strong channel especially in the area of making specialized drama, reality programs and presenting unbiased news to their viewers.

They appreciated SATV for its better screen quality though they showed their concerns that in some most of the rural areas it is very hard to see SATV as it uses its latest technology for ensuring its HD quality screen. They suggested SATV to take care of this issue.

\section{RTV}

RTV is emphasizing to produce more live music programs and reality initiatives.

RTV is the only channel in Bangladesh who has their individual award programs to make motivated with their creativity based on their performances on their screen.

They considered the influence of Indian culture in our Bangladeshi electronic media industry as a threatening element as most of the channels are trying to give the Indian shadow in all the programs especially dramas. It is creating an identity crisis and increasing a gap gradually in coming closer to our root and soil.

\section{STRATEGIZING SA CHANNEL PVT LTD (SATV) AFTER ANALYZING THE COMPETITORS}

SATV is prioritizing strategies for winning over audiences who are fond of Indian channels and programs. Keeping a close look of this issue, it is trying to introduce such programs so that it can reinforce to get their target viewers back in their side through building their signature image and brand identity. The following summarizing points are explained below for giving justification of our brand significance:

Crystal clear high definition (HD) executed screen: SA TV executes the accurate HD (High Definition) technology in the infotainment media and television industry that ensures high quality picture and crystal clear resolution. In order to maintain the screen quality SATV has to spend a huge a lot of money every month. Although all the television channels claim to give HD quality careen, actually they are not giving it because only SATV ensures screen size 1920/1080 which is the actual HD screen while others maintain the screen size 720/576. SATV introduced this screen first time in Bangladesh in the year of 2013 and got the first mover advantage and since from then it has been creating history and gaining competitive advantages over rivals through making this differentiation. Some of the points need to be notified here to differentiate ours from others:

- SATV uses touch screen for news/sports/business/financial updates which is unique in our electronic media

- Encoding \& decoding including our muxing is done fully in true high definition mood. Therefore, our picture output credibility goes to high definition 1920/1080i a career level of MPEG4/DVB-S2 type

An owned luxurious station: Among very few channels in Bangladesh SATV runs its operation in their own $6^{\text {th }}$ storied premises. It is situated at Gulshan 1, one of the busiest the industrial point of Dhaka city and for that reason It gets extra benefits and opportunities of gaining more attention and focus of the industrial owners to promote and advertise their products on SATV screen. It has immense reputation of owning one of the lucrative channels in Bangladesh who has ensured a luxurious interior and exterior design that has been designed by world class designers.

A place with different ethnic manpower where equal employment opportunity' is maintained : SATV always welcomes the top most efficient manpower, experts and believes in the process of expatriation without the concern of country, citizenship, region, religions and other issues. They only prefer talents and gives values accordingly. In 
the year of $2013 \mathrm{Mr}$ Scott Robert Craig was the in charge of News Department and gave a revolutionary change in this particular segment. SATV recruits it.

\section{A differentiating stage and set design with a highly} aristocratic graphical presentation: Compared to other channels SA TV created a benchmark in giving a unique presentation both in stage designing and on screen graphical works. As the screen size is quite differentiating, the production and graphical team get a better chance to decorate the stage and screen from their own way to get attracted by the viewers. On the other hand SATV management doesn't allow many sponsors of allow limited number of sponsors and gives them limited access to put their logo on screen so that too many logos couldn't affect the beauty of the screen. SATV doesn't compromise the outlook and beauty of screen with anything

Secured and safety working environment: SATV gives a strong emphasize in ensuring a safety working environment. Recently national fire security people of Bangladesh trained all SATV employees officially regarding some related issues of fires like how and why fire takes place in a business area and gave some suggestions and techniques about the process of getting rid of through arranging a real life practice session at the office premises. HR and administration department always give a close look and a different department and people are assigned particularly in order to take care of this security matters.

Supplementary brand reputation: SA Channel Pvt Ltd (SATV) is sister concern of SA Group. SA Group is mostly known by SA Paribahan who has a strong brand image in the business of parcel and courier service sector. SATV brings some extra values and got public faith as a co-brand of SA Group specially SA Paribahan.

S.A. Paribahan (SAP) is an unparalleled or matchless organization in courier and parcel service sector in Bangladesh. It is providing successful service since 1982 with the government authorization throughout their belief on courier document and parcel. All sectors of SAP are also very careful to deliver customer's goods to their desired destination. And customer also prefer courier and parcel services for quality and feel comfortable in sending goods from one

place

to

another.

http://www.ccintlbd.com/directory/carrying-andfowarding/s-a-paribahan-parcel-coach-servicess525.html

Very selective and choosy in program selection: Among all the television channels in the Bangladeshi electronic industry, SATV is the $2^{\text {nd }}$ channel after national television 'Bangladesh Television (BTV)' who has its individual preview committee for filtering selecting the quality ones in order to ensure the quality issues from all the submitted projects submitted my different directors, producers and vendors etc. It has a research and expert team who are assigned for brainstorming activities of its future programs and prospects that has the higher probability to attract the future target audiences. SATV doesn't encourage and inspire producers and directors to produce and direct any less quality productions which are not adjustable with our HD screen through proper filtering process in terms of televising advertisement as well. From the beginning till now it has been welcoming quality productions that are somehow exclusive in some areas and it might be rich and dependant on some factors like shooting location, artist selection, production script, overall making etc.

A reputation of delivering the positive combined musical approach in accelerating our national music along with welcoming international music simultaneously: SATV encourages world music especially western classical and Indian combining our national own country music that makes a wonderful worldly musical phenomenon. Blending up with them SATV creates a space to enrich our own music. As a consequence of this SATV invited Indian music sensation Mika Singh to perform in our stage live along with the presence and performance of our renowned artists and arranged first one live musical international concert in Nepal which was differentiated approach taken in the history of electronic media industry. SATV tries always to contribute new diversified steps in our music and already has grabbed viewer's attention in regard of this. 
Have a great word of mouth brand accomplishments in designing special programs from celebrating special events: Since from the beginning till now SATV has a brand image of producing special programs for celebrating our national and international special events like $31^{\text {st }}$ of December (Year end celebration), $14^{\text {th }}$ of February (Valentine's day), 14 ${ }^{\text {th }}$ of April (Bangla New Year), $1^{\text {st }}$ of May (International labor day), $21^{\text {st }}$ of February (International Mother Language day) etc along with celebrating the birth anniversary and remembers the death anniversary of different world renowned poets, leaders and cultural personalities etc.

CSR (Corporate Social Responsibilities) activities: SA TV tries to highly involve with any types environmental, educational and other social related issues as a media partner. Starting from promoting educational campaign to raising voice in favor of unbalanced social, moral, environmental factors SATV wants to give their footsteps and tries to notify it to the concerned department of Government along with their recommendations.

The reputation of the chairman for the common people and society: $\mathrm{Mr}$ Salauddin Ahmed is well known as a social worker both nationally and internationally. He first introduced the courier service business in Bangladesh and got instantly first mover advantage.

Mr Salauddin is the owner and the publisher of Bengali Daily The Janapad. Apart from this, he is involved with many social welfare activities. He is The President of Bangladesh Parcel Service Owners Association Mr. Salahuddin Ahmed wants to contribute more for the wellbeing of this country. Alongside business, Mr. Salauddin Ahmed is contributing enormously by attaching himself with many social development programs and for this he has been venerated by many socio-cultural organizations several times. Mr. Salauddin also visited many countries of the world in connection with his business and personal purposes also.

http://reflectionnews.com/salauddin-ahmedchairman-managing-director-s-a-paribahan/

SA Residence-one of the aristocratic residential brand in Bangladesh: $\mathrm{Mr}$ Salauddin Ahmed, Managing director of SA Group is well known in the media as one of the personality who has a luxurious posh mentality of owning the most aristocratic ownership. The brand reputation of SATV is somehow connected with his regard. He built his residence named 'SA Residence' by architect Rafiq Azam who has received one prestigious 'the Emirates Glass Leading European Architects Forum (LEAF) Award 2012' as an Asian architect:

Bangladeshi architect Rafiq Azam has won the Emirates Glass Leading European Architects Forum (LEAF) Award 2012 for his SA Residence project. Rafiq's SA residence project, a three-storey building in the shape of a square and made from only cast concrete, won the award in the 'Residential building of the year (multiple occupancy)' category, said a press release yesterday.

http://archive.thedailystar.net/newDesign/newsdetails.php?nid=255483

Created example in area of musical reality show in Bangladesh: From the approach of endeavoring to differentiate things toward gaining public interest and faith along with achieving first mover competitive advantage SA TV is the first ever television channel who owned the famous talent hunt musical reality patterned 'IDOL' franchise based on the original UK show Pop Idol who has spawned idol more than 40 countries including United States of America, Canada, Australia Brazil, Germany, France, Indonesia, Malaysia, India, Singapore and so on and televised it in the year of 2013 through the American based production and distribution Delta.

Idols $\bullet$ have aired in more than 129 series, in about 43 territories so far. It's is a knock-out music talent show that follows each contestant's life story and follows it from auditions to the final, thereby involving the audiences into the heart of the format. The auditions for the competition will begin in February.

http://archive.thedailystar.net/newDesign/newsdetails.php?nid=265190

Individual in house production: SA TV has its own multimedia production unit named SA Multimedia \& Production. It started its journey officially on $24^{\text {th }}$ January, 2014. At that time SATV was the first channel that had its own individual multimedia 
production in order to produce its own production that led the greater possibility to gather more revenue in our pocket without the interference of agency.

Company's tagline matches with group's overall motto: The tagline SATV is in Bangla 'Sathe Achi Shobshomoy'. If we translate it in English we can say 'Always everywhere we are with you'. Connecting with the statement SA Channel Pvt Ltd (SATV) has strategized all of its actions, planning and strategies through proper communication of all its group wings. SA Group is comprised with six sister concerns including SATV.

SA Group is better known in the market for the services of SA Paribahan Pvt Ltd who is the oldest parcel and courier service provider company and committed to maintain the smooth delivering process of throughout Bangladesh. The significance of the tagline of SATV is signified in SA Real Estate that has been running since 2009 to give the commercial and residential solution. Besides this it is planning to establish it individual SA Agro Feeds Ltd in order to provide quality food products. In order to be more diversified SA Group is diversifying them into another wing named SA World focusing the boutique productions which is dedicated to give fashionable quality clothing in order to create differentiation in Bangladeshi apparel industry. Besides SA multimedia \& production is committed to produce better quality programs to make SATV fulfilled and independent.

So its entire business theme is connected with SATV tagline and this actually gradually led toward gaining public appreciation.

International recognition: Considering the above mentioned points third generation private television channel SATV has been selected to receive world acclaimed award the 'International Quality Crown' in gold category.

Spain based organization Business Initiatives Directions, (BID), credited with work from past 29 years for building better quality innovation across the globe has scheduled to hand over the award at a gala event through a system of votes and recommendations because of its contributions in terms of leadership, quality and excellence. The international IQC convention will take place in
London on the $21^{\text {st }}$ and $22^{\text {nd }}$ November 2015, with the award presentation held at the Guoman Tower Ballroom.

\section{RESEARCH FINDINGS ANALYSIS AFTER INTERVIEWING SESSIONS}

Political interference: Some channels are facing political pressures in delivering unbiased news for the common people. While interviewing them some channels showed their frustration and accused the unbalanced and unrest political conditions of Bangladesh that are constantly pulling back our electronic media industry and letting it to operate and broadcast in an awkward environment.

Marketing constraint: Government is giving licenses and letting in too many channels to operate in electronic media industry. This phenomenon is giving a threatening impact for each of their survival as the market size is unchanged. Some channels are already facing unavoidable problems in order to touch its expected profitable margins and not even breakeven margin within their probable time boundary. As too many competitors are in the market offering a competitive TVC rate, it is becoming harder for them to survive and the problem rises even more when any old channels want to increase their TVC rate in the midst of too many players.

Channel positioning through program segmentation: Most of the channels are segmenting their strategy based on programs. Some channels are branded in the electronic media based on programs. Some are focused on dramas while some others on music or sports.

Reputation of the mother company and its financial back up: Some channels are doing great based on their financial strength. Keeping it on its favor some channels are prioritizing their initiatives focusing more on making quality programs before going to the field of hunting sponsors though it can lead toward the level of uncertainty to some extent. Some channels have acknowledged the reputation of their mother company in creating their signature image and brand identity.

Technological advancement along with technical expertise: Some channels are strategizing their brand 
based on technological advancement along with its advanced technical support manpower in all the departments through maintaining an elaborate national and international recruiting procedure

Dominance of Indian culture in Bangladeshi electronic industry: Some of the channels are segmenting their program culture based on international demand especially Indian culture. In recent time this has become a common phenomenon for any electronic channel while producing any drama and mega serial and somebody has identified it a big threat raising identity crisis.

Campaigning programs, not channels to create an identity: It is noticeable fact that based on individual strength some channels keep some certain budget to campaign and emphasize the promotional activities not only on its own screen but also in other screen too that can automatically led creating a unique identity.

\section{SATV RESEARCH FINDINGS:}

After surveying 200 people the following results it was received:

$40 \%$ people think that SATV is gaining competitive advantage through screen HD picture quality

$20 \%$ people think that SATV is gaining competitive advantage through making exceptional set design.

$15 \%$ people think that SATV is gaining competitive advantage through on airing exceptional program quality.

$10 \%$ people think that SATV is gaining competitive advantage through making differences on overall industry.

5\% people think that SATV is gaining competitive advantage through presenting unbiased news.

5\% people think that SATV is gaining competitive advantage through cable availability.

5\% people think that SATV is gaining competitive advantage through maintaining uninterrupted transmission.

\section{PLEASE SEE APPENDIX}

So people have a positive impression about SATV for its HD screen picture quality. After analyzing the interviewing part that had been conducted with 12 different channels so recommendations can be drawn regarding which part they need to upgrade and which part they need to modify and that has been explained thoroughly in the following part.

\section{APPLICABLE RECOMMENDING NOTES FOR SATV}

Launching On line version: SATV should launch its online TV version where they can engage SA Multimedia production in order to produce special categorized short films for making a difference and make some change in our monotonous entertainment world.

Start the operation of its newspaper: Since SA group has the license of daily newspaper the daily Janopad, it should start its operation as early as possible. It will create an added wing to promote its products in a better way as SATV need to get more exposure in print media so that it can energize its initiatives in making brand identity.

Channel \& Product positioning: Proper channel and product segmentation and positioning should be finalized if it wants to reach in a better position from now on and strengthen it compared to other channels in the infotainment media industry and it can be done either through focusing in drama/ music/film/news/sports etc. It shouldn't be 'jack of all trade and master of none'

Proper compilation of each business segment: Business segments should be compiled in such a way that creates invisible bonding with each other whose mission and vision are similar and reflects indifferent brand identity.

Cost analysis communicating with marketing department: Based on the probability of getting sponsorship amount of money the production cost should be settled through the concern and consultation with the marketing department so that the ratio and probability of profitability increases. Proper consultation and communication with marketing department are mandatory for this. 
Ensuring rural transmission: Excluding the issue of target age group, geographical \& biographic segmentation SATV should ensure its transmission in every corner of the country especially in the rural areas so that the middle class common people got to know about our programs. Proper communication with all the cable operators is mandatory with our broadcasting team.

Creating self identity: SATV should go forward with making liaison with the government for making it a law in order to reduce the interference of Indian channels in our border as most of the channel is suffering from identity crisis and becoming insecure day by day promoting our own culture that is throwing a threatening future for our future generation

Organizing a national award program: SATV can come forward organizing a award program yearly basis nationally to motivate our national artists that will help them to gain the first mover advantage.

Campaign products, not channel: SATV should more cultivate their strategy emphasizing on campaigning its specialized segmented program rather than channel. If the programs are promoted highly, automatically the channel will get the spotlight of brand identity and come in front row

Channel segmentation: SATV can submit one proposal to Govt. urging to take initiatives on channel segmentation. Govt. can enforce transmission rules for positioning it programs based on particular segment that is either news or dramas or music or mega serial. It is like if one channel will televise drama, no other channel will get the right to televise the same segment. In that way competition will be automatically reduced because each channel will be assigned to televise some particular segment without harming any one's business

Entertainment segment at SATV.TV: SATV can introduce entertainment news segment in its website. It can publish updated recent news taken from our entertainment industry where it can reflect the artist feature, album/movie/drama news etc so that the hitting of our website increases automatically that can led to our individual brand identity.
Venturing with a leading FM station with barter system: SATV can come up with an a yearly barter bilateral agreement with a leading FM station so that both of us can promote each other's products.

Remuneration package deal with cable operator: SATV can make any agreement deal with cable operators so that they can tune up SATV within 1 to 7 serial. The SATV authority will supervise all of their activities and can motivate them with remuneration.

Minute buying in other channels: SATV can promote their programs in other electronic channels so that everyone can take a look at our programs trailors. The whole process can be done through barter systems.

\section{CONCLUSION}

The infotainment industry of Bangladesh is strategized and devoted to serve the audiences concerning different class, people, and program segmentation as well as channel positioning and target viewers. All the channels have their individual and unique brand identity and strength to occupy some certain portion of viewers utilizing its own strategy and in this way they are trying to entertain the whole Bangladesh. Some barriers and lacking were noticed and caught while doing this investigation. As per the concern of recommendations regarding these burning issues, the solutions are not always in our hand and truly speaking some are beyond our capability if the proper logistic and administrative supports are provided from govt. and other related agencies and organizations. Above all the infotainment channels should keep in mind that we are Bangladeshi and we have our own identity, norms, values that should be practiced not only in our real life and but also in our life of our entertainment because if we don't welcome ourselves and keep our entity in a safer way into us, who will welcome us, who will be responsible $\&$ in charge of our norms and who will hold and spread our pride so that we can deliberately push forward our cultural identity outside of our border.

\section{REFERENCES}

Electronic references. (n.d). Retreived August 18, 2015, from http://www.ccintlbd.com/directory/carrying-andfowarding/s-a-paribahan-parcel-coach-services-s525.html 
Electronic references. (n.d). Retreived August 18, 2015, from http://reflectionnews.com/salauddin-ahmedchairman-managing-director-s-a-paribahan/

Electronic references. (n.d). Retreived August 18, 2015, from http://archive.thedailystar.net/newDesign/newsdetails.php?nid $=265190$

Electronic references. (n.d). Retreived August 18, 2015, from http://archive.thedailystar.net/newDesign/newsdetails.php?nid $=255483$

Electronic references. (n.d). Retreived October 18, 2015, from http://www.dhakatribune.com/bangladesh/2013/nov/27/13tv-14-fm-radio-stations-get-licence 
M.N.H Talukder/Competitiveness of SATV is Measured by Certain Factors in the Bangladeshi.....

\section{APPENDIX}

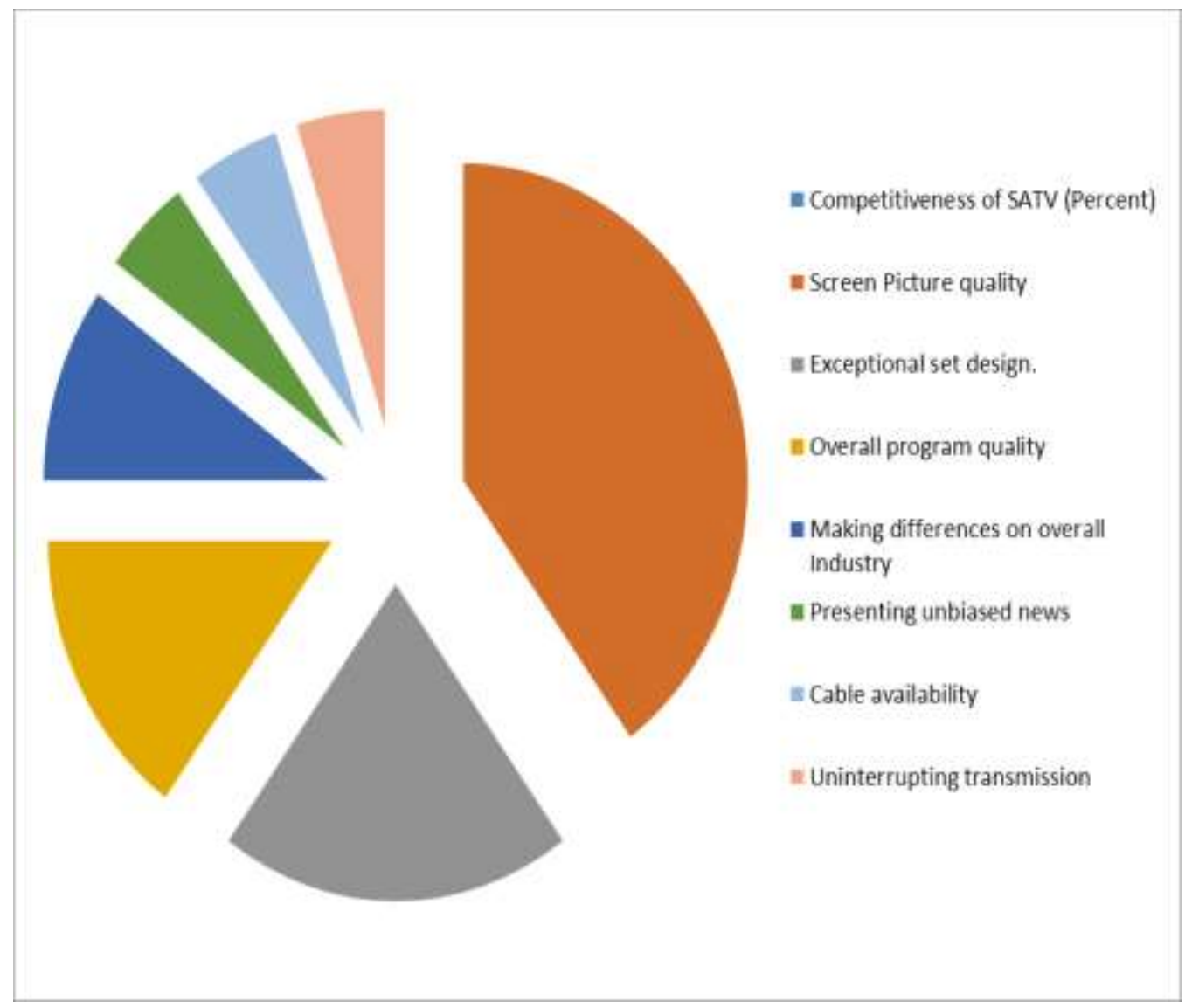

